\title{
A Sensitive Fluorimetric Procedure for the Determination of Aliphatic Epoxides under Physiological Conditions
}

\author{
Hans J. C. F. Nelis ${ }^{1}$ and J. E. Sinsheimer ${ }^{2}$ \\ College of Pharmacy, University of Michigan, Ann Arbor, Michigan 48109
}

Received January 5, 1981

\begin{abstract}
A highly sensitive fluorimetric procedure based on alkylation of nicotinamide is described for the determination of aliphatic epoxides. Subsequent reaction of the resulting $\mathrm{N}$-alkylnicotinamides with a ketone in basic medium yields strongly fluorescent products after final acidification. Sensitivity of the assay is in the picomole range with good reproducibility. The alkylation reaction proceeds under physiological conditions and thus shows potential for the analysis of epoxides in biological materials. Despite rapid enzymatic detoxification, styrene oxide could be directly detected in $9000 \mathrm{~g}$ supernatant liver fractions using the present approach.
\end{abstract}

Aliphatic epoxides have been demonstrated to be intermediates in the biotransformation of several ethylenic compounds (1-4). Their high chemical reactivity accounts for such biological effects as mutagenesis (5-7), binding to cellular macromolecules (8-10), and alkylation of nucleic acids (11). Some epoxides are widely used in industry and thus represent potential hazards for exposed workers.

So far, detection methods are restricted to gas-liquid chromatography $(\mathrm{gc})^{3}(1-4)$ or a colorimetric p-nitrobenzylpyridine (NBP) approach $(7,12,13)$. The gc method, while offering the advantage of specificity, requires extraction when it is applied to biological materials, which might result in substantial degradation. Its sensitivity is generally limited to the nanomole range. The NBP method has improved sensitivity but with the disadvantage of instability of its final color. In addition, the reaction can only

\footnotetext{
' Present address: Laboratoria voor Medische Biochemie en voor Klinische Analyse, R.V.G., DePintelaan 135, B-9000 Gent, Belgium.

2 To whom correspondence should be addressed.

${ }^{3}$ Abbreviations used: gc, gas-liquid chromatography; NBP, $p$-nitrobenzylpyridine; tlc, thin-layer chromatography.
}

be carried out in an essentially nonaqueous medium and is therefore incompatible with physiological conditions (7).

In this paper, we describe a new, highly sensitive method for detecting epoxides, based on the alkylation of nicotinamide (14). Alkylated nicotinamides are converted to strongly fluorescent compounds following reaction with a ketone in basic medium and subsequent acidification (15-18). As the alkylation reaction readily proceeds under physiologial conditions, it can be directly applied to biological materials.

\section{MATERIALS AND METHODS}

Propylene oxide, trichloropropylene oxide (1,2-epoxy-3,3,3-trichloropropane), epichlorohydrin, and cyclohexene oxide were obtained from the Aldrich Chemical Company (Milwaukee, Wisc.) and styrene oxide from the Dow Chemical Company (Midland, Mich.). They were used as received. Nicotinamide (Calbiochem, Los Angeles, Calif.) by tlc on silica with propanol: $10 \%$ ammonia $(95: 5, v / v)$ showed a single spot with no indication of alkylated material at the origin. All other chemicals were analytical grade and purchased from MCB (Norwood, Ohio). 
Preparation of epoxide solutions. Epoxide working solutions $(0.1 \mu \mathrm{mol} / \mathrm{ml})$ were prepared by diluting $2.0 \mathrm{ml}$ of an ethanolic stock solution $(1.25 \mu \mathrm{mol} / \mathrm{ml})$ to $25.0 \mathrm{ml}$ with $0.0667 \mathrm{M}$ phosphate buffer, $\mathrm{pH}$ 7.4. Further dilutions (up to $0.25 \mathrm{nmol} / \mathrm{ml}$ ) were made in buffer as well.

Assay of epoxides in aqueous solutions. One hundred microliters of the phosphate buffer solution containing 0.025-10 nmol of epoxide was mixed with $50 \mu$ l of nicotinamide solution $(125 \mu \mathrm{mol} / \mathrm{ml}$ in $0.0667 \mathrm{M}$ phosphate buffer, $\mathrm{pH}$ 7.4). After incubation for $15-120 \mathrm{~min}$ at $37^{\circ} \mathrm{C}$ (or, alternatively, at 60 or $\left.80^{\circ} \mathrm{C}\right), 0.5 \mathrm{ml}$ of acetophenone solution $(15 \% \mathrm{v} / \mathrm{v}$ in ethanol) and $0.5 \mathrm{ml}$ of $1 \mathrm{M}$ ethanolic potassium hydroxide was added. The contents of the tubes were immediately mixed and the mixture kept in ice for $10 \mathrm{~min}$. Finally, $2.5 \mathrm{ml}$ of formic acid (95-97\%) was added and the tubes placed in a boiling water bath for $5 \mathrm{~min}$ and subsequently cooled in ice. The fluorescence is read and corrected for the contribution of a blank without epoxide after $10-15$ min using an Aminco Bowman spectrofluorimeter with excitation and emission wavelengths set at 370 and $430 \mathrm{~nm}$, respectively.

To increase the sensitivity, all volumes can be further reduced by a factor of 2 to 10 .

Detection of styrene oxide in liver homogenates. The procedure described by Ames et al. (19) was followed to prepare rat S9 liver homogenates. S9 fractions were stored at $-80^{\circ} \mathrm{C}$ until used. Diluted S9 mixes were made by adding $1.4 \mathrm{mmol}$ of nicotinamide and sufficient phosphate buffer $(0.0667 \mathrm{M}, \mathrm{pH} 7.4)$ to 0.5 or $1.1 \mathrm{ml}$ of $\mathrm{S} 9$ fraction to bring the total volume to $2.1 \mathrm{ml}$. An aliquot of $0.3 \mathrm{ml}$ of each $\mathrm{S} 9$ mixture (corresponding to 71 or $157 \mu \mathrm{l}$ of $\mathrm{S} 9$ fraction, respectively) was combined with $0.5 \mathrm{ml}$ of a buffered solution containing 0.10 or 0.42 $\mu$ mol of styrene oxide. Incubations were carried out at $37^{\circ} \mathrm{C}$. Aliquots $(50 \mu \mathrm{l})$ were withdrawn after $30 \mathrm{~min}$ and assayed as described above. Control samples containing either boiled S9 fraction or buffer were run under the same conditions.
To study the actual rate of disappearance of styrene oxide, the procedure was modified in that nicotinamide was omitted from the incubation mixture. Instead, 50- $\mu 1$ aliquots were taken, then mixed with $100 \mu \mathrm{l}$ of nicotinamide solution and incubated for an additional $30 \mathrm{~min}$ at $80^{\circ} \mathrm{C}$. All other steps remained unchanged.

\section{RESULTS}

\section{Rate of Alkylation of Nicotinamide by Epoxides}

Three variables affect the rate of alkylation of nicotinamide by aliphatic epoxides. Figure 1 illustrates the effect of the nicotinamide concentration. Epichlorohydrin was used as a model compound for this experiment. Increasing amounts of the nucleophile increase the rate of alkylation and, therefore, enhance the final fluorescence, but at the expense of higher background. Reaction mixtures usually contained 6.25 or $12.5 \mu \mathrm{mol}$ of nicotinamide. A linear relationship on $\log -\log$ paper was found between fluorescence after subtraction of the blank and the amount of nicotinamide over a wide range.

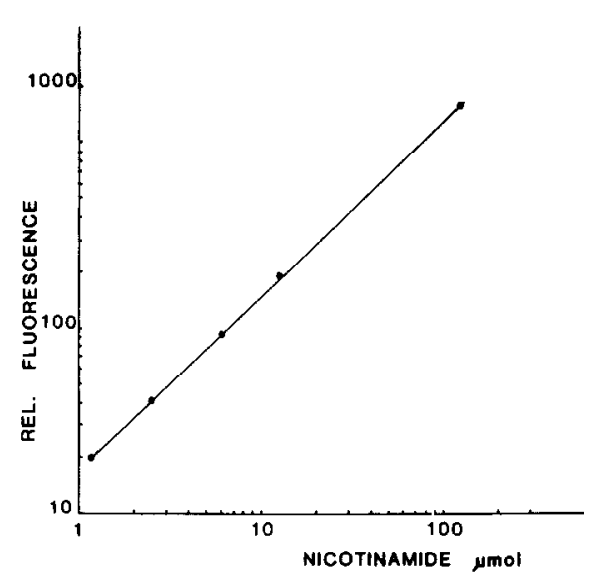

FIG. 1. Effect of the amount of nicotinamide on the alkylation rate by an aliphatic epoxide (epichlorohydrin). Epoxide solutions ( $250 \mu \mathrm{l}$, containing $12.5 \mathrm{nmol}$ of epichlorohydrin) were incubated with $100 \mu \mathrm{l}$ of a solution containing increasing amounts of nicotinamide. Fluorescence was developed as described under Materials and Methods. 
The effect of time and temperature in the alkylation of styrene oxide are shown in Fig. 2. Although most results were obtained under physiological conditions, it was useful for the weakest alkylating agent in this study, i.e., cyclohexene oxide, to increase the temperature which resulted in faster alkylation and hence in an improvement of sensitivity. However, this trend was not confirmed for all the epoxides studied (Table 1). The addition of an organic solvent such as ethanol to the reaction mixture had an unfavorable effect on the akylation rate.

\section{Assay of Epoxides in Aqueous Solution: Linearity and Sensitivity}

A linear response of fluorescence versus concentration was obtained for the four epoxides studied in the range of $0.5-50 \mathrm{nmol} /$ $\mathrm{ml}$ (trichloropropylene oxide), $1-100 \mathrm{nmol} /$ $\mathrm{ml}$ (styrene oxide), 5-100 $\mathrm{nmol} / \mathrm{ml}$ (cyclohexene oxide), and $1-100 \mathrm{nmol} / \mathrm{ml}$ (propylene oxide) (Table 2).

Detection limits at 37 and $80^{\circ} \mathrm{C}$ are given in Table 1. A concentration corresponding to a fluorescence reading of twice the background was defined as the lowest detectable amount, although the linear range usually extended below this value. Reduction of all volumes ( $10 \mu \mathrm{l}$ of epoxide solution, $10 \mu \mathrm{l}$ of nicotinamide solution, $25 \mu$ l of acetophenone

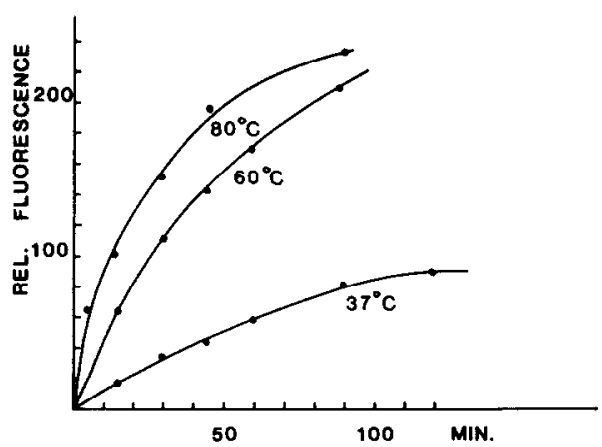

FIG. 2. Effect of temperature and incubation time on the rate of alkylation of nicotinamide by styrene oxide. A styrene oxide solution ( $100 \mu \mathrm{l}$, containing $5 \mathrm{nmol}$ of compound) was reacted with $100 \mu$ l of a nicotinamide solution $(12.5 \mu$ minol).
TABLE 1

DETECTION LIMITS FOR FOUR EPOXIDES

\begin{tabular}{lll}
\hline & \multicolumn{2}{c}{ Detection limits $[$ nmol (ng)] } \\
\cline { 2 - 3 } \multicolumn{1}{c}{ Compound } & $37^{\circ} \mathrm{C}$ & $80^{\circ} \mathrm{C}$ \\
\hline Cyclohexene oxide & $2.0(200)$ & $0.8(78)$ \\
Propylene oxide & $0.5(29)$ & $0.6(35)$ \\
Styrene oxide & $0.5(60)$ & $0.2(24)$ \\
Trichloropropylene oxide & $0.1(16)$ & $0.09(14.5)$ \\
\hline
\end{tabular}

and $\mathrm{KOH}$ solutions, $130 \mu \mathrm{l}$ of formic acid) further improved the sensitivity. Use of a microcell in this case allowed detection of as little as $0.025 \mathrm{nmol}$ of trichloropropylene oxide.

\section{Detection of Styrene Oxide in S9 Fractions}

Results of the assay of styrene oxide in an in vitro biological system containing $\mathrm{S} 9$ fraction are presented in Table 3. Reproducibility at $30 \mathrm{~min}$ was evaluated on the basis of six determinations (50- $\mu$ l aliquots taken from six different samples). A concentration of $0.52 \mu \mathrm{mol} / \mathrm{ml}$ yielded a fluorescence reading of about five times the background. Longer incubation times failed to increase the fluorescence, indicating that all the epoxide had disappeared at this point, either by reaction with nicotinamide or because of enzymatic action. In order to monitor exclusively detoxification as a function of time, an alternative approach, without nicotinamide in the incubation mixture, was employed. Figure 3 shows fluorescence versus time plots for three concentrations of styrene oxide $(0.05,0.25$, and $0.4 \mu \mathrm{mol} / \mathrm{ml})$ in the presence of different amounts of $S 9$ fraction. In previously deactivated (boiled) S 9 preparations, the fluorescence remained constant over the same time interval and was essentially equal to the value obtained with the other control samples (buffer instead of S9 fraction).

\section{DISCUSSION}

Nicotinamide in buffered aqueous solution is readily alkylated by aliphatic epox- 
TABLE 2

LINEARITY DATA FOR Four EPOXIDES

\begin{tabular}{ccccc}
\hline & \multicolumn{4}{c}{ Relative fluorescence $^{a}$} \\
\cline { 2 - 5 } $\begin{array}{c}\text { Concentration } \\
(\mathrm{nmol} / \mathrm{ml})\end{array}$ & $\begin{array}{c}\text { Cyclohexene } \\
\text { oxide }\end{array}$ & $\begin{array}{c}\text { Propylene } \\
\text { oxide }\end{array}$ & $\begin{array}{c}\text { Styrene } \\
\text { oxide }\end{array}$ & $\begin{array}{c}\text { Trichloropropylene } \\
\text { oxide }\end{array}$ \\
\hline 0.5 & - & - & - & 12.5 \\
1.0 & - & 4.6 & 9.0 & 19.5 \\
2.5 & - & 7.5 & 15.0 & 44.0 \\
5.0 & 5.0 & 12.2 & 20.0 & 103.5 \\
10.0 & 6.3 & 14.0 & 47.0 & 204.0 \\
25.0 & 12.4 & 30.0 & 112.0 & - \\
50.0 & 23.7 & 50.0 & 220.0 & 930.0 \\
100.0 & 45.0 & 110.0 & 477.0 & - \\
\hline
\end{tabular}

Note. Equations of the fluorescence (ordinate) vs concentration curves were $y=0.43 x+2.3$ (cyclohexene oxide), $y=1.03 x+4.1$ (propylene oxide), $y=4.7 x-1.6$ (styrene oxide), and $y=18.5 x+5.8$ (trichloropropylene oxide). Correlation coefficients were $0.9997,0.9970,0.9991$, and 0.9998 , respectively:

${ }^{a}$ After subtraction of blank.

ides. Ethylene oxide has been previously reported to yield $N^{1}$-(2-hyroxyethyl)-nicotinamide under similar conditions (14). In basic medium, $N$-alkylnicotinamides react with ketones to give stable adducts after acidification (15-18). Different cyclic structures have been proposed for the reaction product(s) $(15,18,20)$. A high degree of

TABLE 3

AsSay OF STYrene OXIDE IN S9 Liver Fractions

\begin{tabular}{lcc}
\hline \multicolumn{2}{c}{ Relative fluorescence $^{a}$} \\
\cline { 2 - 3 } & $\begin{array}{c}\text { Styrene oxide } \\
\text { concentration, } \\
0.52 \mu \mathrm{mol} / \\
\mathrm{ml}^{b}\end{array}$ & $\begin{array}{c}\text { Styrene oxide } \\
\text { concentration, } \\
0.13 \mu \mathrm{mol} / \\
\mathrm{ml}^{\kappa}\end{array}$ \\
\hline & 216 & 39 \\
& 221 & 37 \\
& 217 & 34.5 \\
& 212 & 42 \\
Mean \pm SD & 200 & 38 \\
Coefficient of variation $^{\text {Background }}$ & 219 & 37 \\
Control $^{d}$ & $214.2 \pm 7.6$ & $37.9 \pm 2.5$ \\
& $3.5 \%$ & $6.6 \%$ \\
\hline
\end{tabular}

a Results after subtraction of the background; after $\mathbf{3 0}$ min of incubation.

${ }^{b}$ Incubation mixture $(800 \mu \mathrm{l})$ containing $157 \mu \mathrm{l}$ of $\mathrm{S} 9$ fraction and $200 \mu \mathrm{mol}$ of nicotinamide.

' Incubation mixture $(800 \mu l)$ containing $71 \mu \mathrm{l}$ of S9 fraction and $200 \mu \mathrm{mol}$ of nicotinamide.

${ }^{d}$ Control samples contained buffer instead of S9 fraction.

e Results after subtraction of a blank value of 12 . 
specificity for alkylated nicotinamides is guaranteed, since both the presence of an amide group and a quaternary ring nitrogen are required for the reaction. The nature of the ketone determines the fluorescent properties of the condensation product. Substitution of acetone by acetophenone resulted in a 5- to 10-fold increase in sensitivity. The same effect was noted previously for other $N$-alkylnicotinamides, e.g., $N$-methylnicotinamide $(17,18)$.

Although only a limited amount of nicotinamide is actually alkylated by the epoxide and a competing solvolysis of the epoxide may be expected (21), the high sensitivity of the fluorimetric approach permits short reaction time ( $5 \mathrm{~min}$ for the more reactive halogenated compounds) under mild conditions $\left(37^{\circ} \mathrm{C}\right)$. This represents major improvement over the colorimetric NBP method.

Furthermore, this fluorimetric assay provides at least a 100-fold increase in sensitivity. The latter extends beyond the nanomole range, whereas the average detection limit of the NBP method is estimated at 10 nmol (13).

The fluorescence of the final solution is reasonably stable over a long time, with only 6\% decrease being observed over a period of $40 \mathrm{~min}$. Application to biological materials does not require extraction or any sample pretreatment. Reproducibility of the assay even in biological media was highly satisfactory, and even at values as low as about twice the background (Table 3). While these S9-homogenate background values were somewhat higher than the corresponding buffer blanks, they were still reasonable even without centrifugation because of the relatively small amount of S9 fraction in the aliquots used for analysis. When turbidity occurred, centrifugation was included before measurement. Upon incubation of S9 fractions with styrene oxide in the presence of nicotinamide, competition occurs between alkylation and detoxification mechanisms, including enzymatic hydrolysis $(22,23)$ and conjugation with glutathione (24). In addi-

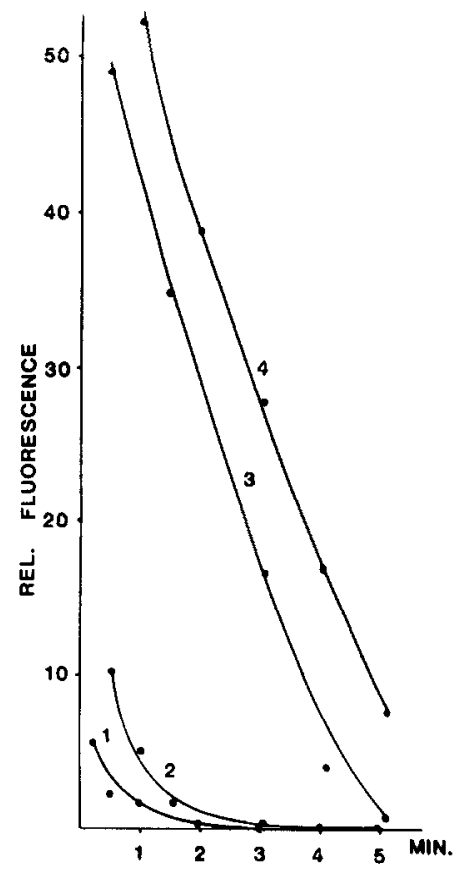

FIG. 3. Rate of disappearance of styrene oxide from a $9000 \mathrm{~g}$ supernatant (S9) system. Incubation mixtures ( $1 \mathrm{ml}$ ) contained either $100(2$ and 4$)$ or $200 \mu \mathrm{l}(1$ and 3) of $\$ 9$ liver homogenate. Styrene oxide concentrations werc 0.05 ( 1 and 2), 0.25 (3), and $0.4 \mu \mathrm{mol} / \mathrm{ml} \mathrm{(4),}$ respectively. Aliquots $(50 \mu \mathrm{l})$ were taken at different times, mixed with $100 \mu$ l of a nicotinamide solution (12.5 $\mu \mathrm{mol}$ ), and incubated for $30 \mathrm{~min}$ at $80^{\circ} \mathrm{C}$.

tion a small amount of substrate might be covalently bound to tissue macromolecules (9). Despite the rapid disappearance of the substrate, it is clear that part of the epoxide is captured in the incubation medium by the nicotinamide. An estimation of the relative extent of the alkylation can be made by comparing the fluorescence obtained for a biological sample and the controls, respectively. From this, it can be inferred that the presence of $\mathbf{S} 9$ fractions reduced the fluorescence to about $20 \%$ of the reading in the control samples, indicating that most of the epoxide has disappeared before it is capable of reacting with the nicotinamide. Since alkylation can only occur as long as free epoxide is available, this indicates that most of the epoxide has been deactivated either by binding or enzymatic conversion.

Study of the actual disappearance rate of 
styrene oxide, using the modified approach, confirmed this rapid detoxification. After only a few minutes (Fig. 3), no more free substrate could be demonstrated. To date in the literature, hydratase activity and coupling with glutathione are separately measured. The present method estimates the residual epoxide present following the combined action of all detoxification mechanisms. Glutathione transferase activity is known to be considerably higher in S9 fractions than hydratase activity (24). This probably accounts for the much shorter half-life of styrene oxide in the $\mathbf{S} 9$ fractions used in this study, as compared to microsomal preparations with their lower transferase levels.

Furthermore, this phenomenon could be rationalized in terms of the low substrate concentrations used. Usually, 10 - to 50 -fold higher amounts of epoxide are required, e.g., in hydratase studies $(23,25)$. Although other mechanisms such as noncovalent protein binding might contribute to the rapid disappearance of the substrate, no evidence presently exists as to the occurrence of such phenomena. The presence of albumin for example did not affect the fluorescence over a 10 -min period. In addition, deactivated S9 preparations always yielded the same results as control samples without liver fraction.

The sensitivity of the method under physiological conditions makes it attractive for the possible in situ detection of epoxides, formed from alkene precursors. However, so far attempts failed to demonstrate any alkylating activity in $\mathrm{S} 9$ mixtures incubated with styrene as a substrate. This was attributed to the exceptionally high background, caused by the presence of the required cofactor NADPH. Oxidized NADP ${ }^{+}$, being an alkylated nicotinamide itself, could contribute to the interfering fluorescence. This compound has been shown to yield a similar fluorescent derivative as $\mathrm{N}$-methylnicotinamide (26). In an attempt to test whether this indeed was the case in our procedure, we used a glucose 6-phosphate dehydrogenase system to reverse the assumed conversion of NADPH to its oxidized form. However, the high fluorescent background remained unaffected by this addition. The work of Schenkman et al. (27) in which they noted that NADPH in the presence of microsomes was rapidly converted to an unidentified fluorescent NADPH analog might explain the high background in our system.

The method described in this paper is not specific for epoxides and could be extended to the detection of alkylating agents in general. It offers a dramatically increased sensitivity over existing assays. Its applicability to the S9-liver detoxification systems, without the need for any sample pretreatment, illustrates the attractiveness of the method for monitoring alkylating agents in an in vitro biological system. The small sample volume required permits multiple readings at different times, thus avoiding extraction of the whole incubation mixture.

\section{ACKNOWLEDGMENTS}

This investigation was supported by Grant 1 Rol CA 25770, awarded by the National Cancer Institute, DHHS. The first author is indebted to the Belgian Fund for Medical Scientific Research (FGWO) and Prof. A. P. DeLeenheer, Gent, Belgium for the opportunity to take part in this investigation.

\section{REFERENCES}

1. Leibman, K. C., and Ortiz, E. (1970) J. Pharmacol. Exp. Ther. 173, 242-246.

2. Maynert, E. W., Foreman, R. L., and Watabe, T. (1970) J. Biol. Chem. 245, 5234-5238.

3. Watabe, T., Isobe, M., Yoshikawa, K., and Takabatake, E. (1978) J. Pharm. Dyn. 1, 98-104.

4. Watabe, T., Isobe, M., Sawahata, T., Yoshikawa, K., Yamada, S., and Takabatake, E. (1978) Scand. J. Work Environ. Health 4 (Suppl. 2), 142-155

5. McCann, J., Choi, E., Yamasaki, E., and Ames, B. N. (1975) Proc. Nat. Acad. Sci. USA 72, 51355139.

6. Wade, D. R., Airy, S. C., and Sinsheimer, J. E. (1978) Mutation Res. 58, 217-223.

7. Hemminki, K., and Falck, K. (1979) Toxicol. Lett. 4, 103-106.

8. Savolainen, H., and Vainio, H. (1977) Toxicology $8,135-141$.

9. Marniemi, J., Suolinna, E.-M., Kaartinen, N., and Vainio, H. (1977) in Microsomes and Drug Oxidations (Ullrich V., Roots I, Hildebrandt, A., 
Estabrook, R. W., and Conney, A. H., eds.), pp. 698-702, Pérgamon, New York.

10. Huang, S. L., Rader, D. N., and Lee, C.-Y. (1978) Chem. Biol. Interact. 20, 333-340.

11. Hemminki, K. (1979) Chem. Biol. Interact. 28, 269-278.

12. Hammock, L. G., Hammock, B. C., and Casida, J. E. (1974) Bull. Environ. Contam. Toxicol. 12, 759-764.

13. Agarwal, S. C., Van Duuren, B. L., and Kneip, T. J. (1979) Bull. Environ. Contam. Toxicol. 23. 825-829.

14. Windmueller, H. G., Ackerman, C. J., Bakerman, H., and Mickelsen, O. (1959) J. Biol. Chem. 234, 889-894.

15. Huff, J. W. (1947) J. Biol. Chem. 167, 151-156.

16. Huff, J. W., and Perlzweig, W. A. (1947) J. Biol. Chem. 167, 157-167.

17. Clark, B. R., Halpern, R. M., and Smith, R. A. (1957) Anal. Biochem. 68, 54-61.

18. Nakamura, H., and Tamura, Z. (1978) Anal. Chem. 50, 2047-2051.
19. Ames, B. N., McCann, J., and Yamasaki, E. (1975) Mutation Res. 31, 347-364.

20. Palfreyman, M. N., and Wooldridge, K. R. H. (1974) J. Chem. Soc. (Perkin I.), 57-61.

21. Bardos, T. J., Datta-Gupta, N., Hebborn, P., and Triggle, D. J. (1965) J. Med. Chem. 8, 167-174.

22. Oesch, F. (1972) Xenobiotica 3, 305-339.

23. Belvedere, G., Pachecka, J., Cantoni, L., Mussini, E., and Salmona, M. (1976) J. Chromatogr. 118, 387-393.

24. Bend, J. R., Smith, B. R., Van Anda, J., Ryan, A. J., and Fouts, J. R. (1978) in Industrial and Environmental Xenobiotics (Fouts, J. R., and Gut, I., eds.), pp. 62-70, Excerpta Medica, Amsterdam.

25. Oesch, F., Kaubisch, N., Jerina, D. M., and Daly, J. W. (1971) Biochemistry 10, 4858-4866.

26. Dolin, M. I., and Jacobson, K. B. (1964) J. Biol. Chem. 239, 3007-3016.

27. Schenkman, J. B., Ball, J. A., and Estabrook, R. W. (1967) Biochem. Pharmacol. 16, 1071-1081. 